\title{
THE AMERICAN SPECIES OF MYRMICA ALLIED TO M. RUBIDA LATREILLE. ${ }^{1}$
}

\section{By William Morton Wheeler.}

The large and handsome Myrmica rubida Latreille remained for many years the only species of an aberrant group within its genus. In 1894 Emery described the first American species of this group, M. mutica, from Denver, Colo., and five years ago I added a species from California, M. bradleyi. Two additional species, M. aldrichi and hunteri, from Idaho and Montana respectively, have since come to light and are described in the following pages. Thus all of the American forms are known only from the mountainous regions of the Western States. The single Old World species occurs in similar localities in Central and Southern Europe and as far east as the Caucasus in Asia Minor and Eastern Siberia. I have had abundant opportunity to study $M$. rubida in the Rhone valley and other localities in Switzerland and M. mutica at Colorado Springs and in neighboring localities in Colorado. Both species have very similar habits. They usually nest in sandy creek bottoms under stones or in small crater nests. The workers of both species sting severely, especially the Eurasian M. rubida, but neither is very aggressive. The pupæ have a peculiar canary yellow color, unlike that of any other species of the genus.

As all five of the species now recognized are closely related to one another and constitute a sharply defined group, I propose to separate them from Myrmica sens. str. as a subgenus, Oreomyrma, subgen. nov., with M. rubida Latr. as the type (Fig. 1a). The workers and females in this subgenus are distinguished by having the epinotum unarmed, the antennal club 5-jointed and the mandibles with two large apical and 12-14 minute basal teeth. The male has no club to the antennal funiculi and the mandibles are like those of the worker. In Myrmica sens. str., with the type M. rubra L., the antennal club of the worker and female is 3-or 4jointed, the mandibles have only 7-12 teeth and the epinotum is armed with a pair of spines. The males have a distinct 4- or 5-jointed antennal club, and their mandibles are only 4-8-toothed.

\footnotetext{
${ }^{1}$ Contributions from the Entomological Laboratory of the Bussey Institution, Harvard University, No. 79 .
} 
The males and females of only two of the species (M. rubida and mutica) are known. The workers of the five species may be readily separated by means of the following key:

1. Anteroventral surface of postpetiole with a pointed or rounded tubercle or

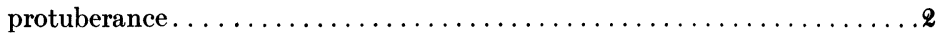

Anteroventral surface of postpetiole flat or at any rate without a tubercle or

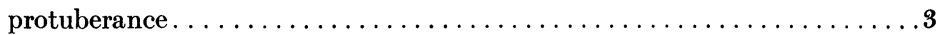

2. Large species (worker, 7-8.5 mm.; female, 9.5-12 mm., male, 8.5-10 mm.) epinotum subdentate; postpetiole with a small; pointed, anteroventral tubercle; deep red, posterior portion of first gastric segment blackish

rubida Latreille.

Smaller species (worker, 4-6 mm.), anterior border of clypeus entire, epinotum not subdentate, rounded in profile; anteroventral portion of postpetiole much more protuberant. . . . . . . . . . . . . . . . . . . . . .

3. Deep red; petiole subopaque. . . . . . . . . . . . . . mutica Emery.

Black, with red thorax, petiole and postpetiole; both petiole and postpetiole shining, more slender...................bradleyi Wheeler.

4. Yellow; anteroventral tubercle of postpetiole conical or pointed aldrichi sp. nov.

Deep red; spot on vertex and posterior portion of first gastric segment black; anteroventral tubercle of postpetiole more rounded........hunteri sp. nov.

Myrmica (Oreomyrma) mutica Emery (Fig. 1 d).

Myrmica mutica Emery, Zoöl. Jahrb. Abth. f. Syst. VIII, 1894, p. 311 우 .

Worker: Length, 4-6 mm.

Head subrectangular, as broad as long, with straight lateral borders and rounded posterior corners. Eyes at the middle of the sides. Clypeus convex, its anterior border very feebly sinuate in the middle. Mandibles with two large apical and about a dozen minute basal teeth. Antennal scapes, rather strongly curved and slightly flattened at the base, scarcely reaching beyond the posterior corners of the head. Funicular club 5-jointed. Thorax in profile with rounded pronotum and the mesonotum gently sloping to a rather deep constriction in sront of the epinotum, which has a subequal base and declivity, the former feebly convex, the latter sloping and nearly straight. Petiole in profile longer than high, its node bluntly rounded, with concave anterior and convex posterior slopes; ventral surface of peduncle in front with a small, acute tooth. Postpetiole scarcely longer than broad, a little broader behind than in front, somewhat broader than the petiole; its ventral surface in profile straight. Gaster a little larger than the head. Legs long, tibiæ and femora feebly clavate.

Subopaque; dental border of mandibles, postpetiole, gaster and legs shining. Mandibles, frontal area and front longitudinally rugose; remainder of the head longitudinally and rather indistinctly punctate-rugulose. Thorax finely rugose, longitudinally on the pleuræ, pro- and mesonotum, transversely and more coarsely on the epinotum. Petiole and ventral portion of postpetiole finely and densely punctate. Gaster and legs with small, scattered, piligerous punctures.

Hairs white, erect or suberect, coarse, rather short, abundant on all parts of the body, legs and scapes. 
Ferruginous red; gaster slightly paler; frontal area, and in some specimens also the antennal clubs, infuscated; mandibular teeth black.

Female: Length, 6.5-7.5 mm.

Closely resembling the worker. Postpetiole in some specimens opaque rugulose, or with only the node smooth and shining. Mesonotum and scutellum sharply and regularly longitudinally rugose, the former with an anteromedian and a pair of parapsidal blackish streaks. Wings grayish hyaline; veins pale brown, stigma dark brown.

Male: Length, 6-7 mm.

Head, including the eyes and excluding the mandibles, distinctly broader than long, rounded behind. Mandibles similar to those of the worker, with two large apical and numerous minute basal teeth. Clypeus very convex, with entire anterior border. Antennæ slender; scapes very short, not longer than the second funicular joint; which is three times as long as the first and of the same length as the succeeding joints. There is no differentiated club. Thorax rather small, narrower than the head through the eyes, with very distinct Mayrian furrows. Scutellum convex, epinotum, petiole and postpetiole much as in the worker. Gaster more slender, with the genital appendages proportionally larger and more exserted than in M. rubida.

Shining; head opaque, indistinctly punctate and longitudinally rugulose; thorax subopaque, more shining above, longitudinally rugose-punctate even on the epinotum. Sides and ventral portions of petiole finely and densely punctate.

Hairs much as in the worker but more delicate and flexuous.

Black; dental borders of mandibles, tibiæ and tarsi brown or sordid yellowish; gaster red, often brownish in the middle above; base of first segment sometimes black or all of the gaster, except the base of the first segment, black. In other specimens the postpetiole is red. Wings colored as in the female.

Colorado: Denver; type locality (Theo. Pergande); Colorado Springs, Salida, Buena Vista and Wild Horse, 6000-7000 ft. (Wheeler); Canyon City (Rev. P. J. Schmitt).

New Mexico: (Ern. André.).

Utah: Salt Lake County (R. V. Chamberlin), as the host of the peculiar xenobiotic ant, Symmyrmica chamberlini Wheeler.

Washington: Olympia (T. Kincaid); Ellensburg and Pullman (W. M. Mann).

Alberta: McLeod (C. G. Hewitt).

British Columbia: Dog Lake, Penticton (C. G. Hewitt).

Myrmica (Oreomyrma) bradleyi Wheeler. (Fig. 1 c.)

Myrmica bradleyi Wheeler, Journ. N. Y. Ent. Soc. XVII, 1909, p. 77, \& .

Myrmica (Oreomyrma) aldrichi sp. nov. (Fig. 1 b.)

Worker: Length 5-6 $\mathrm{mm}$.

Head subrectangular, a little longer than broad, with nearly straight sides and posterior border and rounded posterior corners. Mandibles and antennæ as in 
M. mutica. Clypeus convex, its anterior border very feebly sinuate in the middle. Frontal area indistinct. Thorax similar to that of mutica, but the epinotum with its base feebly and evenly convex and fully twice as long as the distinctly concave declivity. Petiole laterally compressed ventrally, with a small, acute tooth near the anterior end of the peduncle, its node from above subelliptical, longer than broad, in profile with concave anterior and slightly convex posterior slopes. Postpetiole from above but little broader than the petiole, slightly longer than broad, a little broader behind than in front; in profile convex above, especially behind, below with a prominent conical or pointed protuberance near its anterior end.

Mandibles opaque, finely longitudinally striated, their dental border smooth and shining. Head and thorax opaque, longitudinally rugulose-punctate, posterior portion of clypeus, vertex, occiput and pronotum above smooth and shining. Epinotum transversely rugulose. Gaster, legs, petiolar and postpetiolar nodes smooth and shining, with sparse, minute, piligerous punctures; petiole and postpetiole on the sides and below subopaque; finely and densely punctate.

Hairs white, erect, rather short; covering the body, legs and scapes as in M. mutica. Brownish yellow; dental borders of mandibles and antennal clubs pale brown.

Described from sixteen specimens taken by Prof. J. M. Aldrich at Moscow, Idaho.

At first sight this species may be readily mistaken for an immature $M$. mutica on account of its yellow color, but on closer inspection it is easily distinguished by the shape of the epinotum and postpetiole and the smooth front, occiput, pronotum and petiolar mode.

Myrmica (Oreomyrma) hunteri sp. nov. (Fig. $1 \mathrm{c}$ ).

Worker: Length 4-6 $\mathrm{mm}$.

Closely related to $M$. aldrichi but differing in the following characters: Body and appendages brownish red or ferruginous, with a large, black, subtriangular spot on the vertex and a band of the same color across the posterior portion of the first gastric segment. Frontal area, posterior clypeal suture, antennal clubs and dental border of mandibles more or less infuscated. Sculpture sharper and coarser than in aldrichi. Upper surface of head with coarse, scattered punctures in addition to the rugæ. Smooth areas on the head, thorax and pedicel much as in that species. Hairs pale yellow instead of white. Anterior clypeal border entire. Base of epinotum somewhat flattened, anteroventral protuberance of postpetiole broadly rounded and not conical or pointed.

Described from a dozen specimens taken by Dr. S. J. Hunter from a couple of nests on the slopes of two mountains on the Madison River, nearly opposite the mouth of Beaver Creek, Montana, at an altitude of about 7,500 feet. The nests were in shaley earth and apparently of the crater type.

Of all the American species of Oreomryma, hunteri is most closely related to the palearctic rubida in coloration and sculpture. Per- 
haps it should be regarded merely as a subspecies of aldrichi, but its exact status can be determined only with the aid of additional material and with specimens of the males and females of both forms.

Further researches in the mountains of the northwest will probably bring to light additional species of Oreomyrma. The number and distribution of those at present known indicate that the Rocky Mountains are the center of distribution of the subgenus and that $M$. rubida may have reached the Old World during the Tertiary by way of the Behring Strait land-bridge.
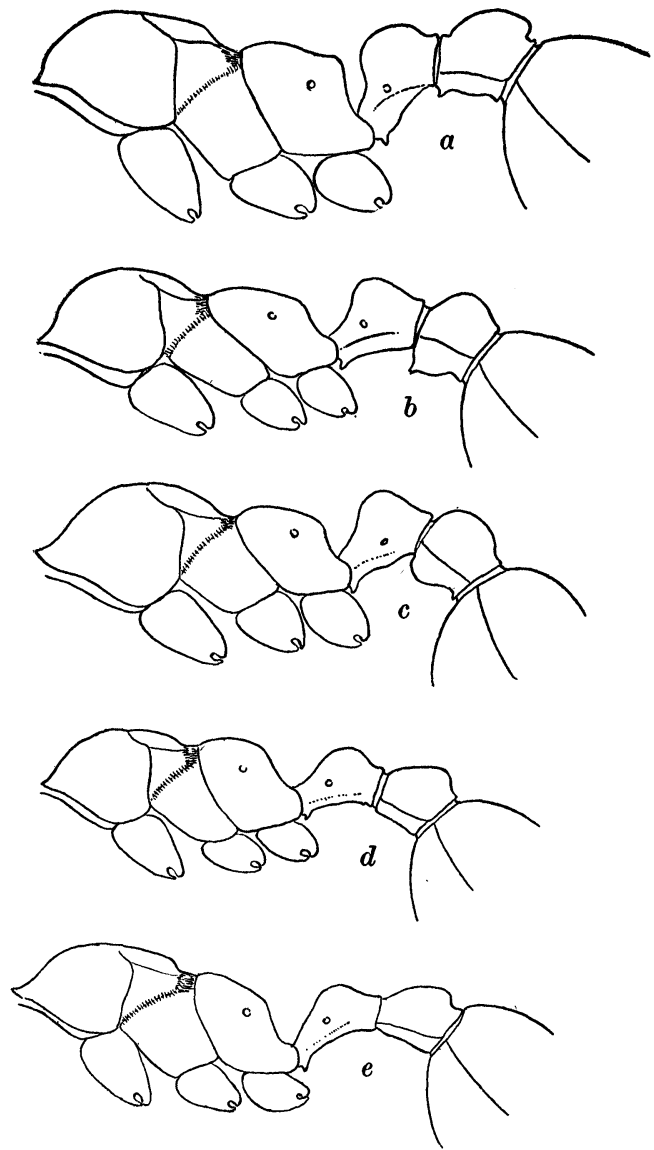

Fig. 1. $a$, Thorax and pedicel of Myrmica (Oreomyrma) rubida Latr. in profile; $b$, of $M$. (O.) aldrichi sp. nov.; $c$, of $M$. (O.) hunteri sp. nov.; $d$, of $M$. (O.) mutica Emery; $e$, of $M$. (O.) bradleyi Wheeler. 

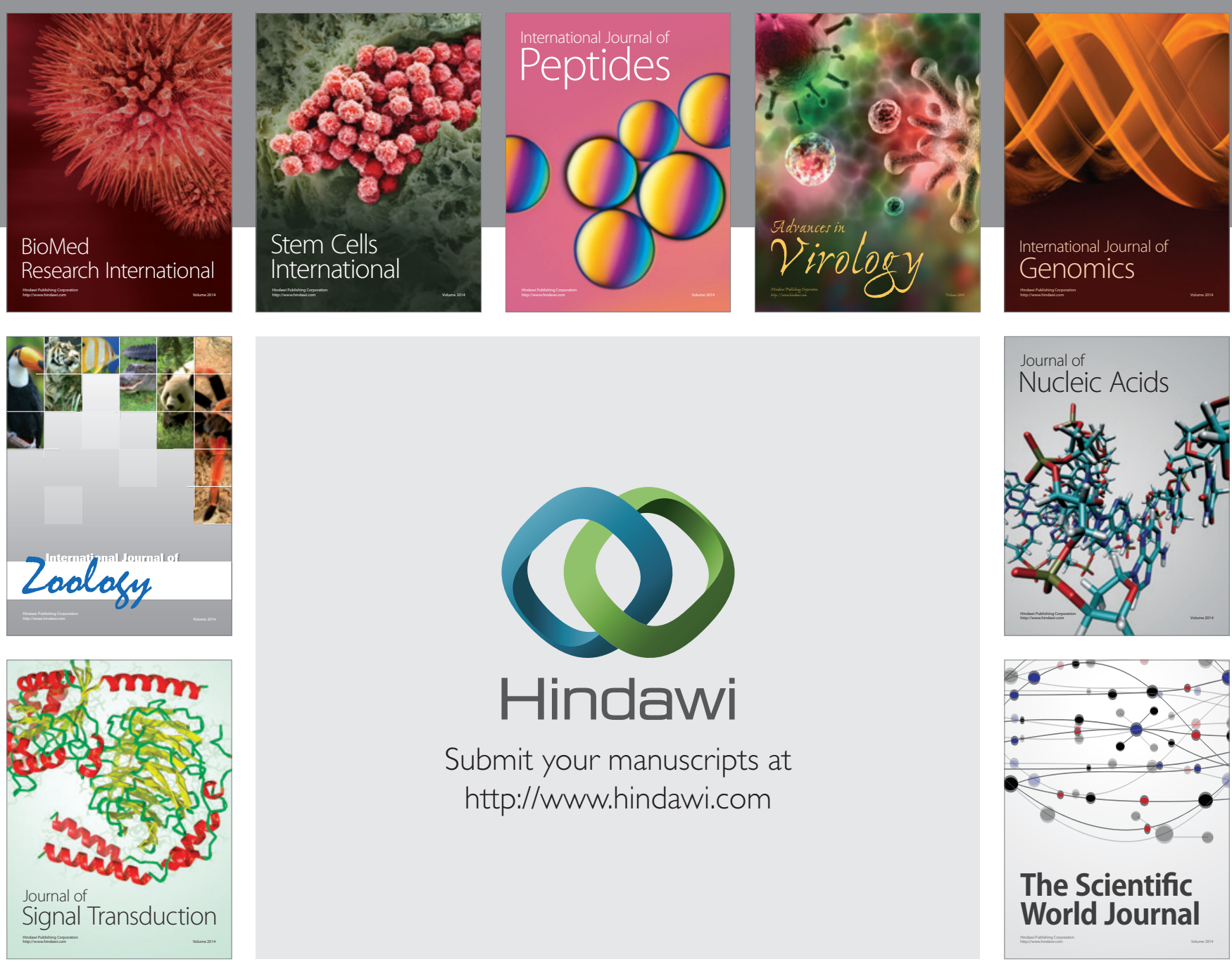

Submit your manuscripts at

http://www.hindawi.com
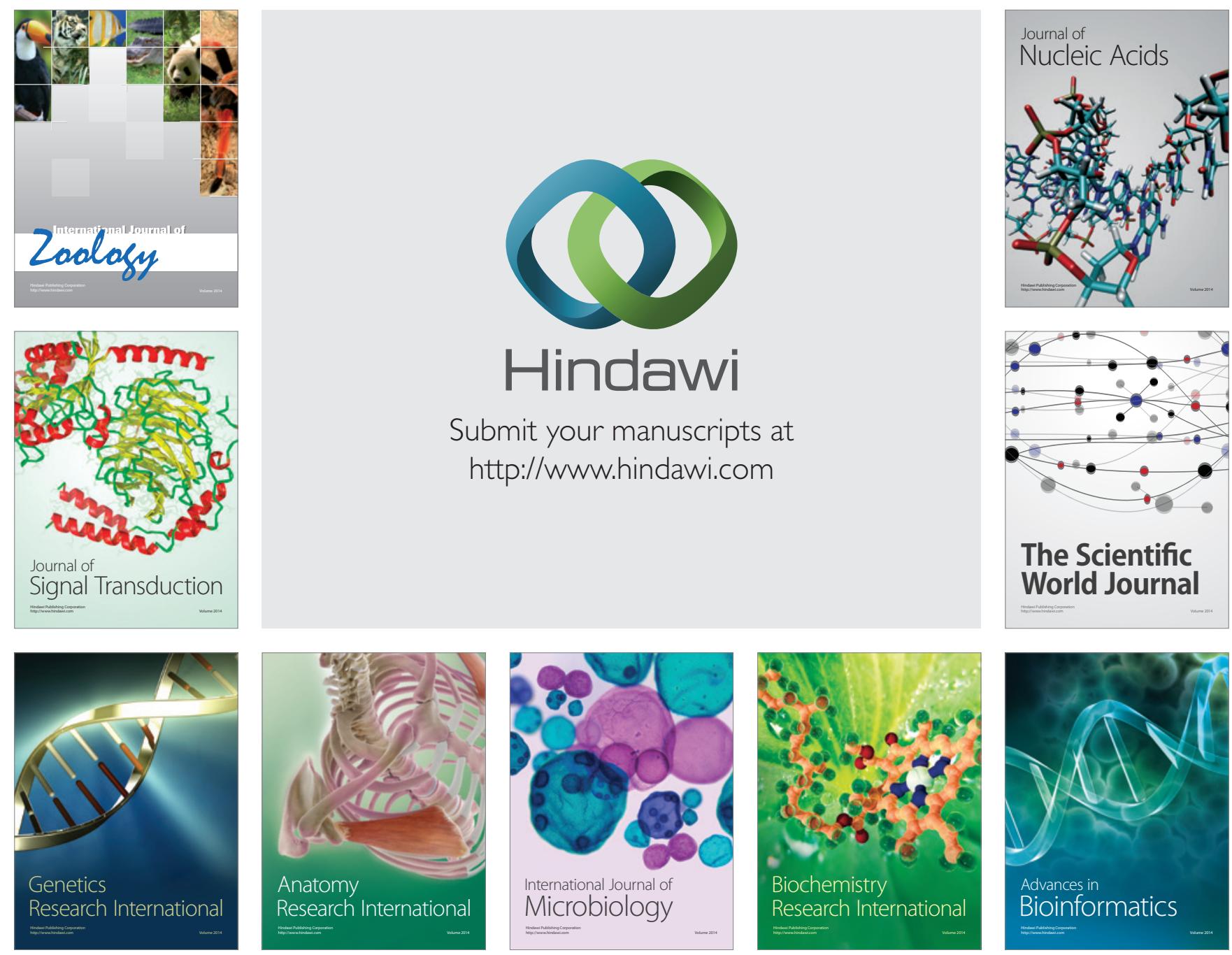

The Scientific World Journal
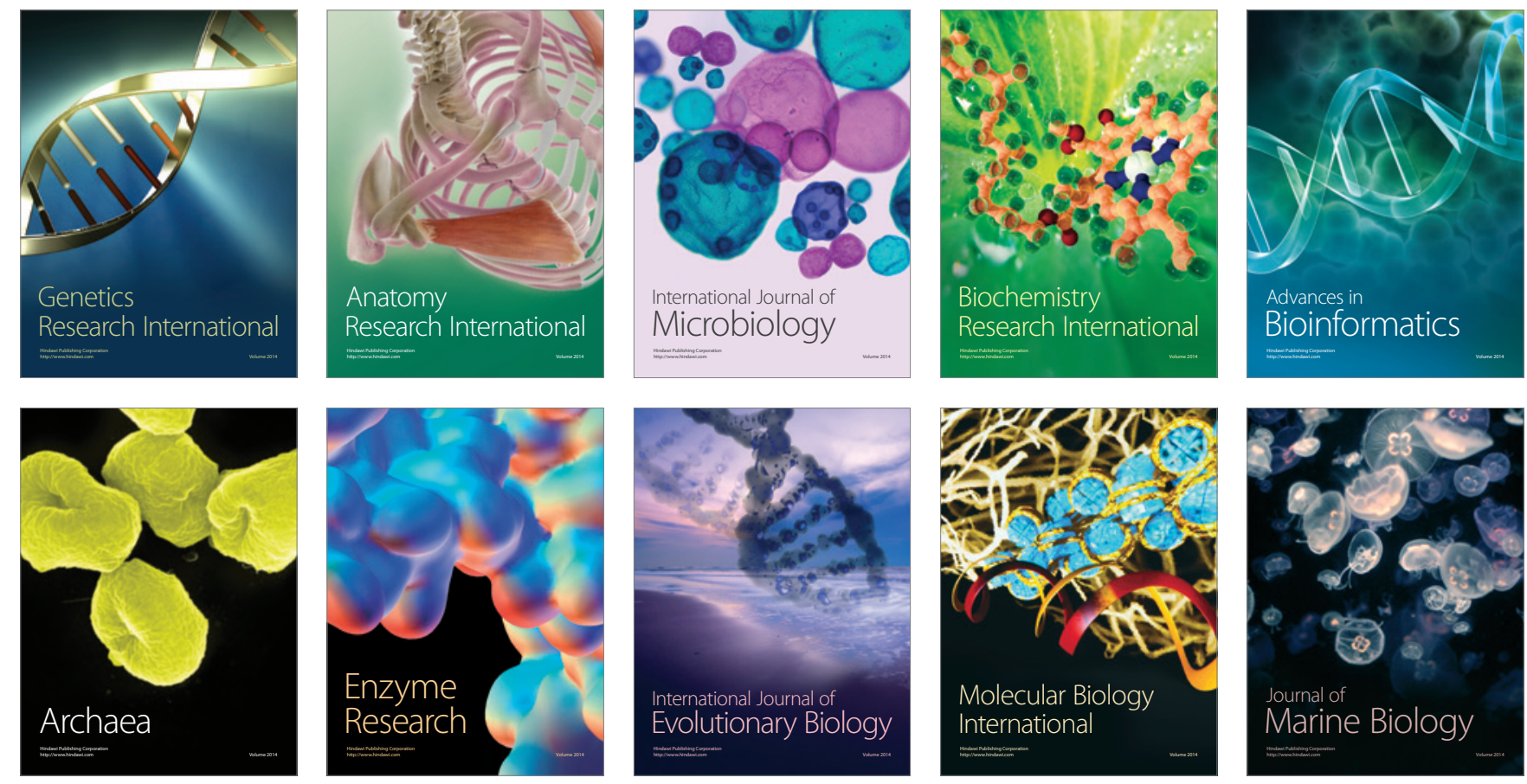